\title{
Comparison of ultrasound-guided versus blind interventions for supraspinatus tendinopathy: a cadaveric study.
}

\author{
F. Abat ${ }^{1}$, J. Campos ${ }^{2}$, J. Torras ${ }^{3}$, M. Madruga ${ }^{3,4}$, G. Planells ${ }^{3}$, A. Rodriguez-Baeza ${ }^{5}$ \\ 1 Sports Orthopaedic Department. ReSport Clinic. Universitat Autònoma Barcelona, Barcelona \\ 2 Sports Medicine Department. ReSport Clinic. Universitat Autònoma Barcelona, Barcelona. Spain \\ 3 Physiotherapy and Rehabilitation Department. ReSport Clinic. Universitat Autònoma Barcelona. Barcelona. Spain \\ ${ }^{4}$ University School of Health and Sport (EUSES), University of Girona, Girona, Spain. \\ 5 Human Anatomy Unit. Department of Morphological Sciences. Faculty of Medicine. Universitat Autònoma \\ Barcelona. Bellaterra, Barcelona. Spain
}

\author{
CORRESPONDING AUTHOR: \\ Ferran Abat \\ Sports Orthopaedic Department. \\ ReSport Clinic. Universitat Autònoma \\ Barcelona, \\ Barcelona, Spain \\ Passeig Fabra i Puig 47 \\ 08030 Barcelona. Spain. \\ Phone: +34 932778709 \\ E-mail: abat@resportclinic.com \\ DOI: \\ 10.32098/mltj.03.2019.06
}

LEVEL OF EVIDENCE: 2B

\begin{abstract}
SUMMARY
Background. The treatment of supraspinatus tendinopathy remains a challenge for the health professional. This study aims to analyze the precision of needle interventions in lesions of the supraspinatus tendon when conducting them in an ultrasound-guided or non-ultrasound guided (blind) manner.

Methods. Study on cadaver with infiltrations performed under ultrasound control or blind after randomization of the parts and participants. Twenty fresh cadaveric shoulders and 30 practitioners with experience using musculoskeletal ultrasound and doing needle interventions. Each practitioner performed 4 ultrasound-guided and 4 unguided punctures. This provided 240 punctures that were analyzed in 3 different anatomical cuts, thus providing a database of 720 measurements for statistical analysis.

Results. Statistically significant differences were observed $(p<0.0001)$ in the distance to the bullet point between the ultrasound-guided and the non-guided infiltrations. It was estimated that the unguided punctures were performed on average $10 \mathrm{~mm}$ farther from the bullet point than the 'ultrasound-guided' punctures. The ultrasound-guided punctures demonstrated $95 \%$ precision while the unguided punctures had a precision rate of $12.5 \%$ $(\mathrm{p}<0.0001)$.

Conclusion. Interventions of the supraspinatus tendon should be performed in an ultrasound-guided manner to facilitate administration of the treatment in the proper area.
\end{abstract}

\section{KEY WORDS}

injections; interventions; tendon; treatment; usget; ultrasound guided

\section{BACKGROUND}

The treatment of supraspinatus tendinopathy remains a challenge for the health professional. The current literature advocates for multidisciplinary work among physicians, physiotherapists and rehabilitators to treat this pathology $(1,2)$. Invasive therapies (in which the injured tendon is punctured) either for the application of galvanic currents $(3,4)$, biological therapies $(4,5)$ or analgesics $(6,7,8)$ are a widespread therapeutic tool today.

The supraspinatus tendon insertion area (SSP) at the level of footprint is the area most frequently affected in a rotator cuff (RC) injury (Figure 1). Jeong et al. (9) has shown the anterior area of the SSP, at about $9-10 \mathrm{~mm}$ posterior to the biceps tendon, as the area at greatest risk of injury (Figures 2A-B).

Until relatively recently, needle interventions had only been carried out blind (anatomical landmark-guided). However, with the arrival of ultrasound and its rise, it has been shown that using it improves precision in the infiltration procedure (10. Ultrasound provides an easy-to-use tool with high image quality, does not irradiate and has a moderate economic cost (11). Precision in carrying out injected 
therapies should be the highest priority. Literature already reports that infiltrations that are not properly done in some areas may worsen the symptoms or make the applied therapy ineffective $(12,13)$.

Multiple treatments have been described that may be useful in the treatment of supraspinatus tendinopathy (4). The main basis of most of these treatments is that the product or technique to be applied must be administered in a specific area of the tendon (area of injury). Mainly, these treatments are with Platelet Rich Plasma (PRP), Ultrasound-guided galvanic electrolysis (USGET), or corticosteroids $(4,7,8)$. As far as the authors know, this is the first work that analyzes the precision of ultrasound-guided and blind punctures inside the supraspinatus tendon (area of injury or bullet point) with the aim of providing guidelines for action in future interventions.

\section{MATERIALS AND METHODS}

The Ethics and Experimentation Committee of our University (num. 03272015) approved the study and meet the ethical standard of this journal (14). The study was carried out in the dissection room of the Faculty of Medicine of our university using 20 upper members from cadavers donated to science. All the donors were serologically tested to rule out infectious-contagious diseases (HIV, hepatitis B and hepatitis C) before starting the study. Of the 20 donors, 12 were women and 8 men, with an average age of 82.3 years

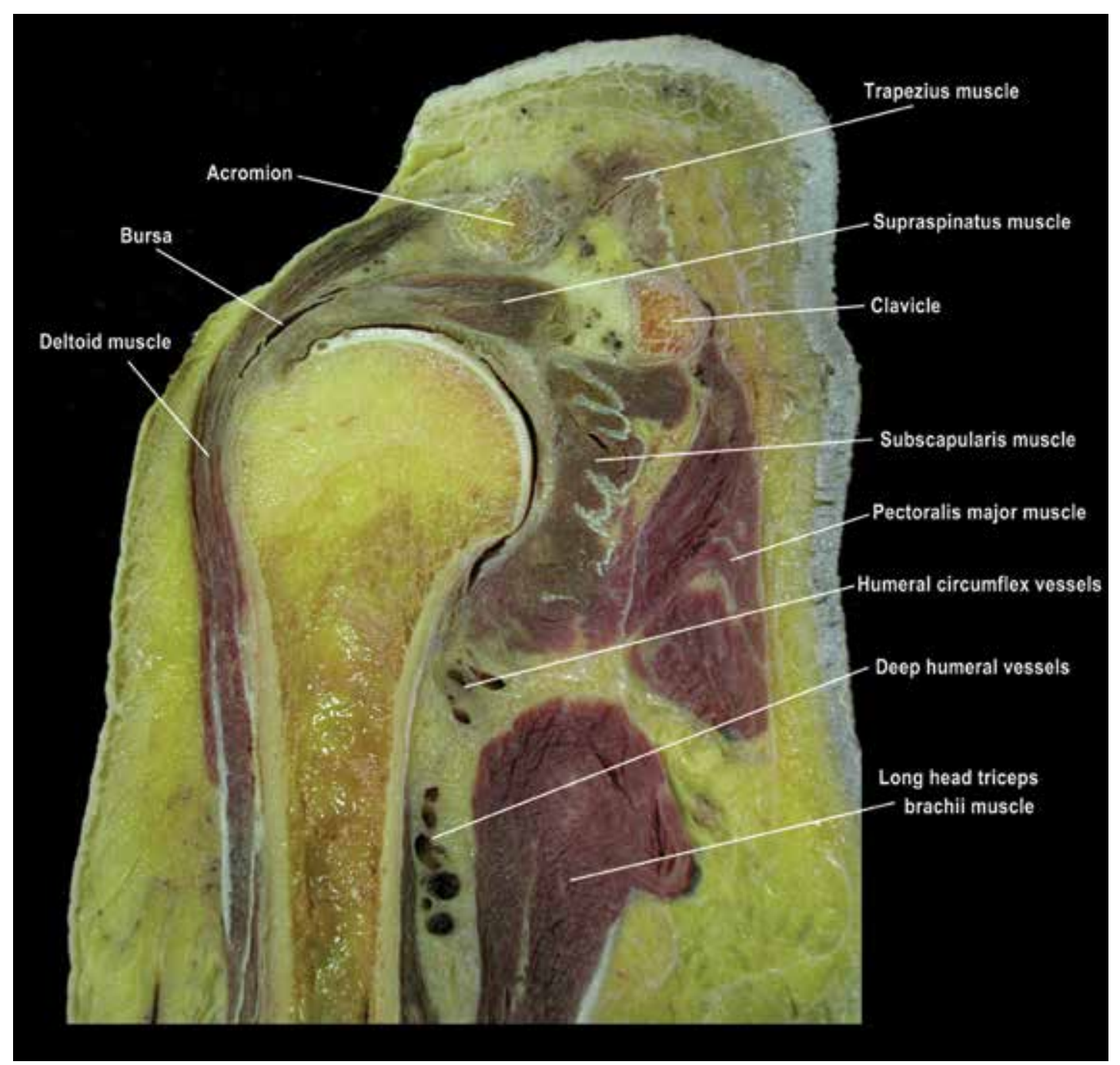

Figure 1. Coronal section of the glenohumeral joint showing the most relevant anatomical structures. 


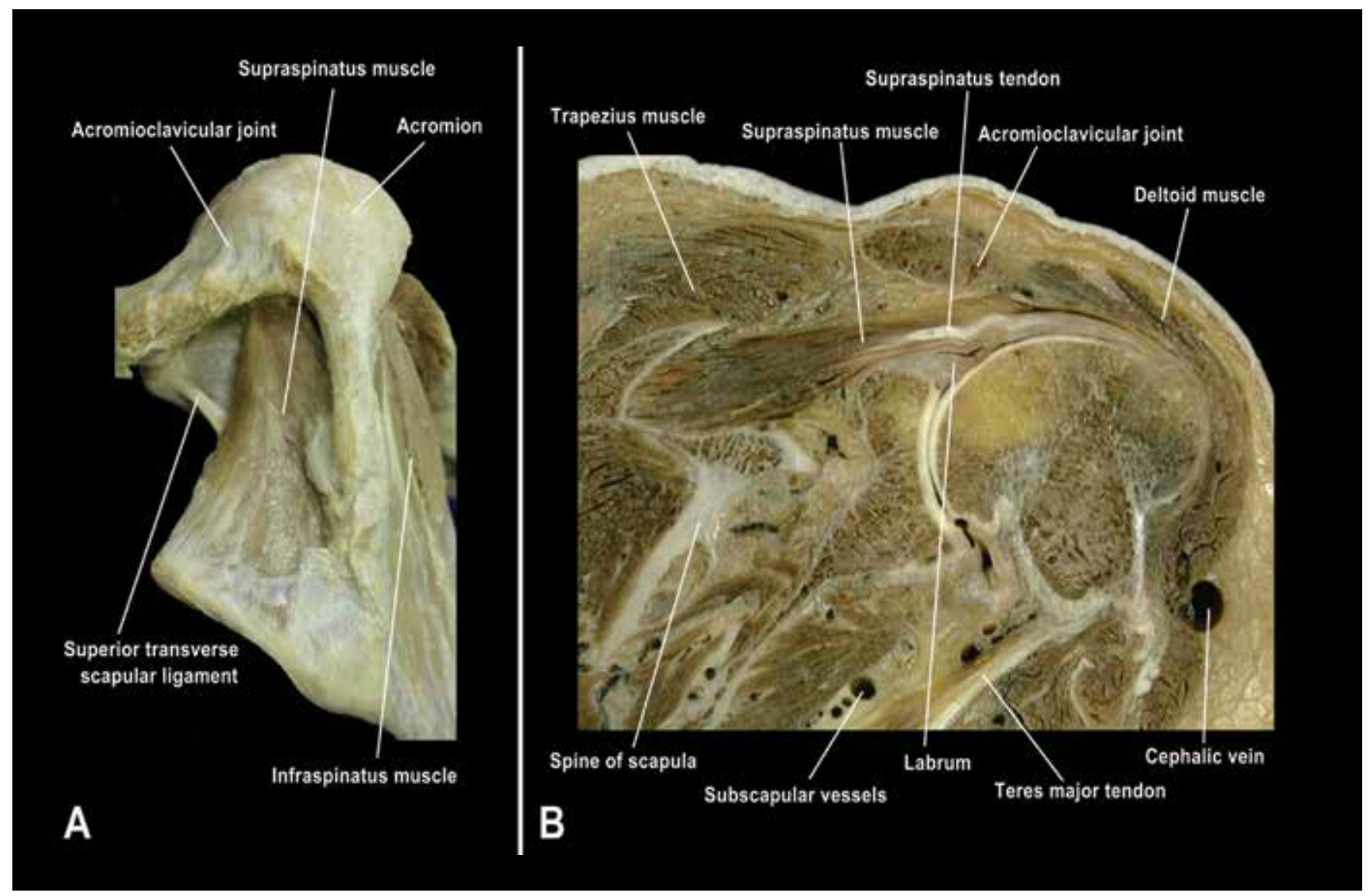

Figure 2. A. Top view of the right supraspinous fossa where the tendons are identified Supraspinous and infraspinous. B. Coronal section of the gleno-humeral joint showing the prolongation of the supraspinatus muscle to its tendinous and insertion part.

(range 71-100 years). There were 9 right shoulders and 11 left shoulders.

The presence of scars and/or shoulder deformities that could interfere with the results of the study was then assessed and the upper limbs of the trunk were separated with scapulo-thoracic disarticulation and clavicular sectioning near the sternoclavicular joint. The upper extremities were stored frozen at $-40^{\circ} \mathrm{C}$ for up to 2 hours before use.

To perform the study, each upper limb was placed in a support that fixed the body of the scapula, thus exposing the shoulder in an anatomical position.

Thirty practitioners performed the infiltrations. The practitioners had an average age of 36.9 years (range of 25 to 59 years), experience of 6.9 years (range of 2 to 25 years) in invasive therapies with needles and average experience of 3.3 years (ranging from 1 to 15 years) in the use of musculoskeletal ultrasound.

The practitioners were informed of the objective of the study. It was to perform infiltrations of the supraspinatus muscle tendon to assess the usefulness of ultrasound. Ultrasound examination was performed with a $5-16 \mathrm{MHz}$ linear array transducer in longitudinal and transversal view in a real-time imaging mode in a standardized mode as described by Rutten et al. (15).

With the help of $5 \mathrm{ml}$ luer-lock syringes with $21 \mathrm{G}$ needles of 30 millimeters, a 1cc infiltration of colored natural latex was performed with randomization of the parts and the practitioners. Each practitioner conducted four ultrasound-guided and four unguided interventions, each on a different specimen, which made it possible to have a database of 240 infiltrations. To assess infiltration precision, the anterior part of the supraspinatus tendon (SSP) was considered the bullet point, about 9 to $10 \mathrm{~mm}$ posterior to the tendon of the long head of the biceps brachii muscle and centered on the thickness of the SSP.

Once the infiltrations were done, the extremities were frozen at $-40^{\circ} \mathrm{C}$ for 1 month. Then, serial cuts, $1 \mathrm{~cm}$ thick on the sagittal plane, were made with the help of a verti- 
cal band saw (Medoc BR 400, Medoc SA, Logroño, Spain) with a $4 \mathrm{~mm}$ blade. Immediately after making the cuts, we proceeded to identify the three most significant serial cuts that allowed us to collect information on the location of the latex and photograph it (digital camera Canon G11 5x 6.1-30.5 mm 1: 2.8-4.5). This information (30 practitioners $x$ 8 infiltrations $\times 3$ cuts) made for a database of 720 measurements (360 echoguided and 360 blind) for its subsequent statistical analysis (Figure 3A-B)

For the computer analysis of the images, Fiji software was used. It is open source software focused on the analysis of biological images $\left({ }^{\circ} 4\right)$. Using this software, the distance between the point to be infiltrated (previously predetermined bullet point) and where the infiltration had been done was calculated.

Statistical analysis was performed with SAS software v9.4 (SAS Institute Inc., Cary, NC, USA). The statistical decisions were made taking the value 0.05 as the level of significance. A validation of the internal consistency of the variables in the database as well as the out-of-range values and missing values was done to fully ensure their reliability. The main response variable was analyzed, this being the average distance to the point of the tendon to be treated (bullet point) in the different anatomical cuts, categorizing this mean as precision.
In the first place, since several punctures were made on the same tendon, the contrast of the inclusion of said random effect on the model was studied. Upon not obtaining statistically significant differences, the punctures were considered independent. A Kolmogorov-Smirnov test for normality of each study and a descriptive analysis of the data were performed. A box diagram of the mean distance to the center of the tendon and the table with the basic descriptive statistics (N, Medium, Std, Minimal, Q1, Medium, Q3, Maximum and Missing) is presented depending on whether the puncture was ultrasound-guided or unguided. The non-parametric contrast was performed for two independent samples: The Wilcoxon test was done to check whether there were differences in the distances to the center of the tendon between the punctures, ultrasound-guided and unguided.

For the evaluation of precision, a descriptive analysis of the data was performed, presented with a precision bar chart and the table with the basic descriptive statistics (N, Percentage) based on whether the puncture was ultrasound-guided or not. The Chi-Square independence test was carried out to check whether there were differences in the puncture precision distribution based on whether it was ultrasound-guided or not. The indicator, Precise (Completely Successful)
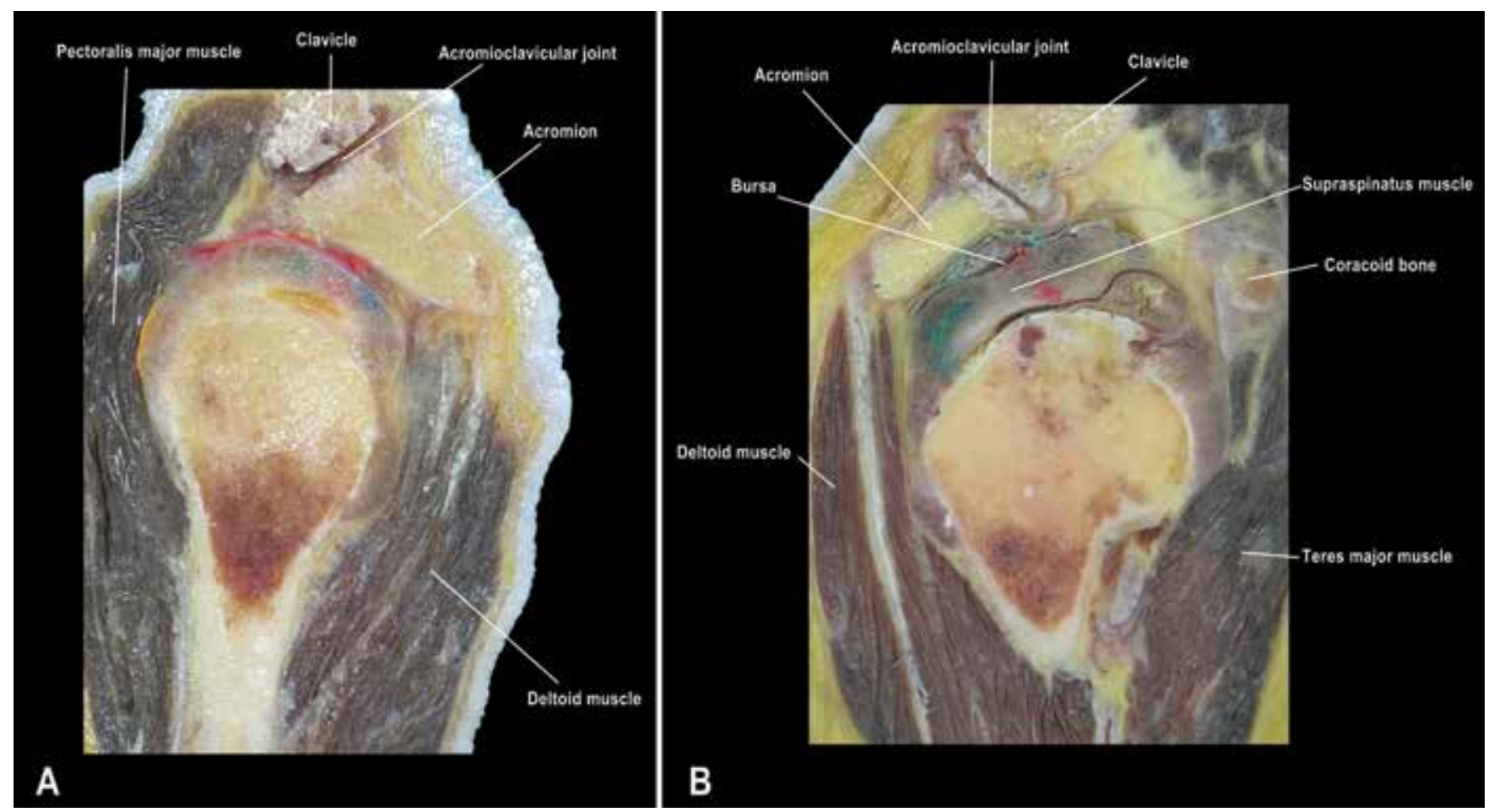

Figure 3 A-B. Coronal section of the glenohumeral joint. In colors, the punctures are identified (colored latex). It can be observed that without the ultrasound control, the infiltrations were made in the SSE tendon as well as in adjacent structures. 
versus Not Precise (Partially Successful and Unsuccessful), was calculated.

\section{RESULTS}

A great difference was observed in the punctures depending on whether they were ultrasound-guided or non-guided (Figure 4). The median distance to the bullet point of the 120 unguided punctures is $14(\mathrm{Q} 1=6.47, \mathrm{Q} 3=16.2)$. It is 2.91 in those that were Ultrasound-guided (Q1=2.47, Q3=3.41) (Table I).

Statistically significant differences are observed (Wilcoxon Two-Sample Test $=21072.5$; p_value $<0.0001$ ) in the distance to the bullet point between those that were ultrasound-guided and those that were not. Specifically, it was seen that the mean in the unguided was 10 units higher than in ultrasound-guided. In addition, the median for the unguided puncture group was 14 when the ultrasound-guid- ed puncture group had a maximum value of 9.5. All the ultrasound-guided punctures were below the median of the unguided punctures.

In ultrasound-guided punctures, we obtained an estimate of the mean distances to the bullet point of $3.05,95 \% \mathrm{CI}=$ $[2.01,4.09]$. In contrast, we obtained an estimate in unguided punctures of the mean distances to the bullet point of $13.36, \mathrm{IC} 95 \%=[12.32,14.4]$.

Statistically significant differences were detected (t Value $=-13.8 ;$ p_value<0.0001) between ultrasound-guided and unguided punctures. The difference between ultrasound-guided and unguided punctures was $-10.31 \mathrm{~mm}$, IC95\% $=[-11.78,-8.84]$. This means that it was estimated that the unguided punctures are performed on average $10 \mathrm{~mm}$ farther from the bullet point than the ultrasound-guided punctures.

A great difference was observed when analyzing successful punctures Vs the unsuccessful in terms of whether it

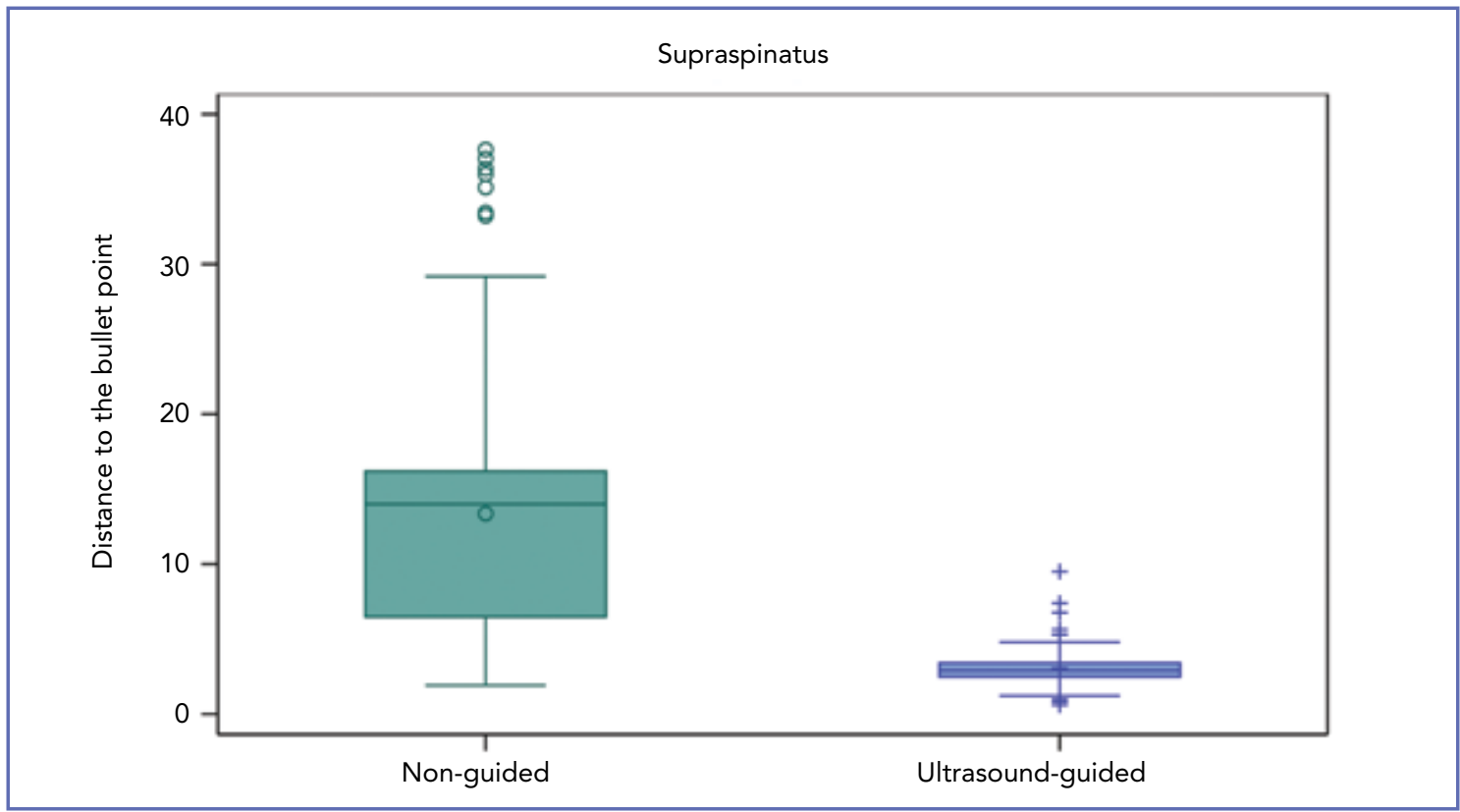

Figure 4. Bar chart showing the distance to the bullet point from the punctures.

Table I. Distance of the ultrasound-guided or blind infiltrations to the bullet point. The number, mean, standard deviation as well as median, minimum, maximum and quartiles are shown.

\begin{tabular}{llllllllll}
\hline & \multicolumn{10}{c}{ Distance to bullet point } \\
\hline & $\mathrm{N}$ & Median & Std & Min & Q1 & Median & Q3 & Max & Missing \\
\hline Unguided & 120 & 13.36 & 8.1 & 1.91 & 6.47 & 14.00 & 16.20 & 37.64 & 0 \\
\hline US-guided & 120 & 3.05 & 1.19 & 0.61 & 2.47 & 2.91 & 3.41 & 9.50 & 0 \\
\hline
\end{tabular}


was performed unguided or ultrasound-guided (Figure 5). Imprecise punctures corresponded to unguided punctures. Most of the unguided punctures were imprecise, 74 punctures $(61.67 \%$ of the total of unguided punctures). Most of the ultrasound-guided punctures are successful, 114 punctures $(95 \%$ of the total of ultrasound-guided punctures). There were statistically significant differences (Chi-Square Test $=166.87 ; \mathrm{p}$ value $<0.0001)$ in the distribution of the precision variable between the ultrasound-guided and unguided. Some $61.67 \%$ of unguided punctures were not precise. However, $95 \%$ of the ultrasound-guided punctures were successful.

In unguided punctures, an estimate of the puncture percentage was obtained (with Precise $=$ Successful) of $12.5 \%, 95 \%$ $\mathrm{CI}=[7.66 \%, 19.75 \%]$. On the other hand, an estimate of the puncture percentage was obtained in ultrasound-guided punctures (with Precise $=$ Successful) of $95 \%$, IC95\%= [89.28\%, 97.75\%] (Table II).
Statistically significant differences were detected ( $\mathrm{t}$ Value $=9.75 ; \mathrm{p}$ value $<0.0001$ ) between ultrasound-guided and unguided punctures. The Odds Ratio for Precision = Successful between ultrasound-guided and unguided punctures is 133 , IC95\% $=[49.51,357.29]$. This means that the Odds Ratio for Precision = Successful in ultrasound-guided punctures was estimated at 133 times the odds in the unguided.

\section{DISCUSSION}

The main objective of this study was to demonstrate the importance of the use of ultrasound in needle interventions of the supraspinatus tendon. Our hypothesis that ultrasound-guided interventions demonstrate greater precision than blind infiltrations has been validated.

Enough evidence can be found in the literature to support the need to use ultrasound in shoulder infiltrations $(4,17$ -

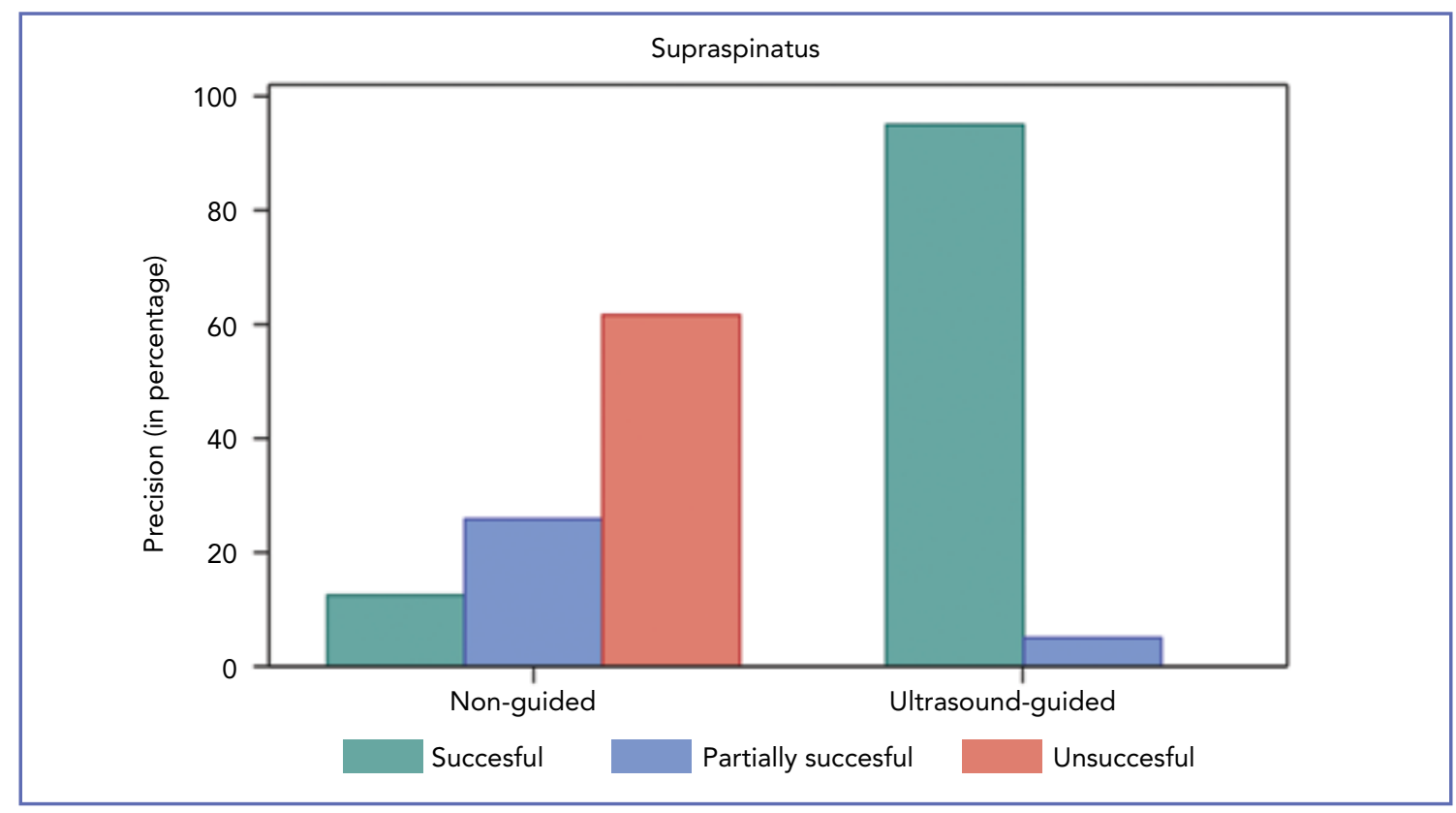

Figure 5. Bar chart showing the distance to precision of the ultrasound-guided or blind infiltrations.

Table II. Precision of ultrasound-guided or blind infiltrations. Results classified as successful, partially successful or unsuccessful.

\begin{tabular}{|c|c|c|c|c|c|c|c|}
\hline \multicolumn{8}{|c|}{ Precision } \\
\hline & \multicolumn{2}{|c|}{ Successful } & \multicolumn{2}{|c|}{ Partially successful } & \multicolumn{2}{|c|}{ Unsuccessful } & Total \\
\hline & $\mathrm{N}$ & $\%$ & $\mathrm{~N}$ & $\%$ & $\mathrm{~N}$ & $\%$ & $\mathrm{~N}$ \\
\hline US-guided & 114 & 95 & 5 & 0 & 0 & 0 & 120 \\
\hline
\end{tabular}


19). In contrast, a recent Cochrane review concluded that the cost of ultrasound does not justify its use (20). Despite this, this study has important limitations such as obtaining a conclusion based on a single study $(17,21)$.

To date, it must be kept in mind that the clinical results of an invasive technique that is not performed in an ultrasound-guided manner cannot be analyzed. Multiple studies show that, without ultrasound control, a very significant number of infiltrations end up outside the "target" site $(8,17,19)$. Therefore, the clinical results do not correlate with said procedure20. The current literature already states that glenohumeral infiltrations administered in the correct area improve the clinical outcome $(22,23)$, while infiltrations outside this area can even cause tissue injuries (22).

Several authors have written of rotator cuff lesions originating in the anterior part of the cuff (insertion) spreading posteriorly with the passage of time $(24,25)$. Recently, other authors have shown that the degenerative lesions originating in the infraspinatus tendon (ISP) spread towards the anterior aspect of the cuff $(26,27)$. Subsequently, Kim et al., in an ultrasound study, described how a lesion of the RC generally occurred at the junction between the supraspinatus (SSP) and the infraspinatus (28). Finally, an important recent study found that the main area of injury shown in MRI is in the SSP insertion in a more anterior area, $9-10 \mathrm{~mm}$ posterior to the biceps tendon (24). This has been the area that has been taken as an area to be treated in the present study. Thus, the ability to puncture only in said area with and without ultrasound has been analyzed.

Currently there are different therapeutic options for the treatment of SSE tendinopathies (5). It is vital that their application be done correctly and in the precise area to be treated. In a recent systematic review, authors such as Filardo et al. found no differences between PRP infiltrations in the SSE tendon or surgery (29). Then again, Fitzpatrick et al. advocate for the use of leukocyte-rich PRP (LR-PRP) under ultrasound control in the treatment of these lesions in their meta-analysis (30). The ultrasound guided galvanic electrolysis technique (USGET) has also recently been proposed as a therapeutic option. It causes a controlled inflammatory reaction in the tendon to trigger the regenerative process $(3,4)$. With subsequent eccentric work, the tissue is stimulated to give mechanical support to the biological treatment. Arias-Buría et al. showed poor results with the use of electrolysis in tendinopathies of the supraspinatus (31). The difference in applied intensity should be highlighted since Abat et al. (3) advocate for amperages of between 2 to 8 milliAmps while Arias-Buria et al. (31) use 350 microAmps in their study. Although there is a substantial debate about the use of corticosteroids in tendon pathology, they are widely used $(32,33)$. Currently, it is thought that the irrigation implied in the use of corticosteroids in tendons no longer justifies their use $(7,34)$.

Another novel therapeutic approach includes the use of hyaluronic acid $(35,36)$, this treatment enhanced viability, proliferation and expression of collagen type I in tendon derived cells.

Consensus on rotator cuff tears management was published recently by Oliva et al. (37) and should be taked as accessible guidelines in order to improve the quality of care and rationalize the use of the different treatment options.

The main limitation of the present study is the use of fresh cadaveric specimens. In those specimens, muscular tension during the injection cannot be determined by the practitioner. Being cadavers of the advanced in age (average of 82.3 years), the tendon of the supraspinatus can be found thin, making blind infiltration even more difficult.

Ultrasound-guided needle interventions have gained popularity in recent years (11). Although some studies indicate the lack of clinical differences that justify the cost of the ultrasound, no cost-effectiveness studies have so far been conducted $(10,13,16-19,21,22)$ (Table III). For the time being, we must rely on studies of the precision of ultrasound-guided versus blind infiltrations. They clearly favor the use of ultrasound to improve precision.

In conclusion the present study clearly supports the use of ultrasound with needle procedures on the supraspinatus tendon, thus improving precision and making it possible to focus the treatment used in the correct area of injury. The novelty of this study resides in the evaluation of the injection therapy precision just on the spot of lesion (injured area), making the treatment more specific and valuable.

\section{ACKNOWLEDGMENTS}

To the department of anatomy of the UAB (Campus Bellaterra) for its collaboration in the project, especially to Manel Querol for his involvement and diligence.

Special mention to donors who have made this study possible with their altruism. We must also make mention of all the colleagues who helped us during the infiltrations in the cadaverous parts. We are also grateful to Eric L. Goode for his help in editing the manuscript. 
Table III. Literature review of ultrasound versus blinded injections around the shoulder. (GH = glenohumeral, US = Ultrasound, RCT $=$ Randomized Controled Trial)

\begin{tabular}{llllllll}
\hline \multicolumn{7}{c}{ Blinded versus Ultrasound Guided Injections } \\
\hline Lead Author & Year & N & Treatment area & Treatment aplied & Imaging Used & Results & Study Design \\
\hline Balint $^{38}$ & 2002 & 6 & GH joint & Fluid Aspiration & US / Blinded & US superior to blinded & Cohort \\
\hline Naredo $^{39}$ & 2004 & 41 & Sub-acromial & Corticosteroid & US / Blinded & US higher accuracy & Cohort \\
\hline Lee $^{40}$ & 2009 & 43 & GH joint & Corticosteroid & US / Blinded & $\begin{array}{l}\text { US obtain greater clinical } \\
\text { improvement }\end{array}$ & RCT \\
\hline Soh $^{18}$ & 2011 & 101 & Sub-acromial & Corticosteroid & US / Blinded & $\begin{array}{l}\text { US obtain greater clinical } \\
\text { improvement }\end{array}$ & Sist. review \\
\hline Patel $^{22}$ & 2012 & 80 & GH joint & Cadaveric Study & US / Blinded & US higher accuracy & Cohort \\
\hline Mattie $^{13}$ & 2015 & 162 & GH joint & $\begin{array}{l}\text { Diagnostic } \\
\text { contrast fluid }\end{array}$ & $\begin{array}{l}\text { Fluoroscopy / } \\
\text { Blinded }\end{array}$ & Image guided better results & Cohort \\
\hline Raeissadat $^{23}$ & 2016 & 41 & GH joint & Corticosteroid & US / Blinded & $\begin{array}{l}\text { US obtain greater clinical } \\
\text { improvement }\end{array}$ & RCT \\
\hline Cole $^{41}$ & 2016 & 56 & Sub-acromial & Corticosteroid & US / Blinded & $\begin{array}{l}\text { No differences in the } \\
\text { clinical outcome }\end{array}$ & RCT \\
\hline
\end{tabular}

\section{REFERENCES}

1. Abat $\mathrm{F}$, Alfredson $\mathrm{H}$, Cucchiarini $\mathrm{M}$, et al. Current trends in tendinopathy: consensus of the ESSKA basic science committee. Part I: biology, biomechanics, anatomy and an exercise-based approach. J Exp Orthop 2017; 4(1):18. doi: 10.1186/s40634-017-0092-6.

2. Miller RM, Thunes J, Musahl V, Maiti S, Debski RE. Effects of tear size and location on predictions of supraspinatus tear propagation. J Biomech 2018; 8;68:51-57. doi: 10.1016/j.jbiomech.2017.12.017.

3. Abat F, Valles SL, Gelber PE, et al. Molecular repair mechanisms using the Intratissue Percutaneous Electrolysis technique in patellar tendonitis. Rev Esp Cir Ortop Traumatol 2014; 3358(4):201-5. doi: 10.1016/j.recot.2014.01.002.

4. Abat F, Alfredson H, Cucchiarini M, Madry H, Marmotti A, Mouton C, Oliveira JM, Pereira H, Peretti GM, Spang C, Stephen J, van Bergen CJA, de Girolamo L. Current trends in tendinopathy: consensus of the ESSKA basic science committee. Part II: treatment options. J Exp Orthop 2018 Sep 24:5(1):38. doi: 10.1186/s40634-018-0145-5.

5. Marmotti A, Peretti GM, Mattia S, Mangiavini L, de Girolamo L, Viganò M, et al. Pulsed Electromagnetic Fields Improve Tenogenic Commitment of Umbilical Cord-Derived Mesenchymal Stem Cells: A Potential Strategy for Tendon RepairAn In Vitro Study. Stem Cells Int 2018; 30;2018:9048237. doi: 10.1155/2018/9048237.

6. Nuelle CW, Cook CR, Stoker AM, Cook JL, Sherman SL. In Vivo Toxicity of Local Anesthetics and Corticosteroids on Supraspinatus Tenocyte Cell Viability and Metabolism. Iowa Orthop J 2018;38:107-112.

7. Coombes BK, Bisset L, Vicenzino B. Efficacy and safety of corticosteroid injections and other injections for management of tendinopathy: a systematic review of randomised controlled trials. Lancet 2010; 20;376(9754):1751-67. doi: 10.1016/ S0140-6736(10)61160-9.

8. Lin MT, Chiang CF, Wu CH, Huang YT, Tu YK, Wang TG. Comparative Effectiveness of Injection Therapies in Rotator Cuff Tendinopathy: A Systematic Review, Pairwise and Network Meta-analysis of Randomized Controlled Trials. Arch Phys Med Rehabil 2018; 1. pii: S0003-9993(18)30920-1. doi: 10.1016/j.apmr.2018.06.028.

9. Jeong JY, Min SK, Park KM, Park YB, Han KJ, Yoo JC. Location of Rotator Cuff Tear Initiation: A Magnetic Resonance Imaging Study of 191 Shoulders. Am J Sports Med 2018;46(3):649-655. doi: 10.1177/0363546517748925.

10. Daley EL, Bajaj S, Bisson LJ, Cole BJ. Improving injection accuracy of the elbow, knee, and shoulder: does injection site and imaging make a difference? A systematic review. Am J Sports Med 2011 Mar;39(3):656-62. doi:10.1177/0363546510390610.

11. Sharpe RE Jr, Nazarian LN, Levin DC, Parker L, Rao VM. The increasing role of nonradiologists in performing ultrasound-guided invasive procedures. J Am Coll Radiol 2013 Nov;10(11):859-63. doi: 10.1016/j.jacr.2013.04.016.

12. Eustace JA, Brophy DP, Gibney RP, Bresnihan B, FitzGerald O. Comparison of the accuracy of steroid placement with clinical outcome in patients with shoulder symptoms. Ann Rheum Dis. 1997 Jan;56(1):59-63.

13. Mattie R, Kennedy DJ. Importance of Image Guidance in Glenohumeral Joint Injections: Comparing Rates of Needle Accuracy Based on Approach and Physician Level of Training. Am J Phys Med Rehabil 2016 Jan;95(1):57-61. doi:10.1097/ PHM.0000000000000338.

14. Padulo J., Oliva F., Frizziero A., Maffulli N. Muscles, Ligaments and Tendons Journal - Basic principles and recommen- 
dations in clinical and field Science Research: 2018 update. MLTJ 2018; 8(3): 305 - 307

15. Rutten MJ, Maresch BJ, Jager GJ, Blickman JG, van Holsbeeck MT. Ultrasound of the rotator cuff with MRI and anatomic correlation. Eur J Radiol 2007 62:427-436.

16. Schindelin J, Arganda-Carreras I, Frise E, Kaynig V, Longair M, Pietzsch T, Preibisch S, Rueden C, Saalfeld S, Schmid B, Tinevez JY, White DJ, Hartenstein V, Eliceiri K, Tomancak P, Cardona A. Fiji: an open-source platform for biological-image analysis. Nat Methods 2012 Jun 28;9(7):676-82. doi:10.1038/ nmeth.2019.

17. Aly AR, Rajasekaran S, Ashworth N. Ultrasound-guided shoulder girdle injections are more accurate and more effective than landmark-guided injections: a systematic review and meta-analysis. Br J Sports Med 2015 Aug;49(16):1042-9. doi: 10.1136/bjsports-2014-093573.

18. Soh E, Li W, Ong KO, Chen W, Bautista D. Image-guided versus blind corticosteroid injections in adults with shoulder pain: a systematic review. BMC Musculoskelet Disord 2011 Jun 25;12:137. doi: 10.1186/1471-2474-12-137.

19. Daniels EW, Cole D, Jacobs B, Phillips SF. Existing Evidence on Ultrasound-Guided Injections in Sports Medicine. Orthop J Sports Med 2018 Feb 22;6(2) doi: 10.1177/2325967118756576.

20. Bloom JE, Rischin A, Johnston RV, Buchbinder R. Image-guided versus blind glucocorticoid injection for shoulder pain. Cochrane Database Syst Rev 2012 Aug 15;(8):CD009147. doi: 10.1002/14651858.CD009147.pub2.

21. Ekeberg OM, Bautz-Holter E, Tveitå EK, Juel NG, Kvalheim S, Brox JI. Subacromial ultrasound guided or systemic steroid injection for rotator cuff disease: randomised double blind study. BMJ 2009 Jan 23;338:a3112. doi:10.1136/bmj.a3112.

22. Patel DN, Nayyar S, Hasan S, Khatib O, Sidash S, Jazrawi LM. Comparison of ultrasound-guided versus blind glenohumeral injections: a cadaveric study. J Shoulder Elbow Surg 2012 Dec;21(12):1664-8. doi: 10.1016/j.jse.2011.11.026.

23. Raeissadat SA, Rayegani SM, Langroudi TF, Khoiniha M. Comparing the accuracy and efficacy of ultrasound-guided versus blind injections of steroid in the glenohumeral joint in patients with shoulder adhesive capsulitis. Clin Rheumatol 2017 Apr;36(4):933-940. doi: 10.1007/s10067-016-3393-8.

24. Curtis AS, Burbank KM, Tierney JJ, Scheller AD, Curran AR. The insertional footprint of the rotator cuff: an anatomic study. Arthroscopy 2006 Jun;22(6):609.e1.

25. Jeong JY, Min SK, Park KM, Park YB, Han KJ, Yoo JC. Location of Rotator Cuff Tear Initiation: A Magnetic Resonance Imaging Study of 191 Shoulders. Am J Sports Med 2018 Mar;46(3):649-655. doi: 10.1177/0363546517748925.

26. Shimizu T, Itoi E, Minagawa H, Pradhan RL, Wakabayashi I, Sato K. Atrophy of the rotator cuff muscles and site of cuff tears. Acta Orthop Scand 2002 Jan;73(1):40-3.

27. Wening JD, Hollis RF, Hughes RE, Kuhn JE. Quantitative morphology of full thickness rotator cuff tears. Clin Anat 2002 Jan;15(1):18-22.

28. Kim HM, Dahiya N, Teefey SA, Middleton WD, Stobbs G, Steger-May K, Yamaguchi K, Keener JD. Location and initiation of degenerative rotator cuff tears: an analysis of three hundred and sixty shoulders. J Bone Joint Surg Am 2010 May;92(5):1088-96. doi: 10.2106/JBJS.I.00686.
29. Filardo G, Di Matteo B, Kon E, Merli G, Marcacci M. Platelet-rich plasma in tendon-related disorders: results and indications. Knee Surg Sports Traumatol Arthrosc 2018 Jul;26(7):1984-1999. doi: 10.1007/s00167-016-4261-4.

30. Fitzpatrick J, Bulsara M, Zheng MH. The Effectiveness of Platelet-Rich Plasma in the Treatment of Tendinopathy: A Meta-analysis of Randomized Controlled Clinical Trials. Am J Sports Med 2017 Jan;45(1):226-233. doi:10.1177/0363546516643716.

31. Arias-Buría JL, Truyols-Domínguez S, Valero-Alcaide R, Salom-Moreno J, Atín-Arratibel MA, Fernández-de-Las-Peñas C. Ultrasound-Guided Percutaneous Electrolysis and Eccentric Exercises for Subacromial Pain Syndrome: A Randomized Clinical Trial. Evid Based Complement Alternat Med 2015;2015:315219. doi:10.1155/2015/315219.

32. Buchbinder R, Green S, Youd JM. Corticosteroid injections for shoulder pain. Cochrane Database Syst Rev 2003;(1):CD004016.

33. Crawshaw DP, Helliwell PS, Hensor EM, Hay EM, Aldous SJ, Conaghan PG. Exercise therapy after corticosteroid injection for moderate to severe shoulder pain: large pragmatic randomised trial. BMJ 2010 Jun 28;340:c3037. doi:10.1136/ bmj.c3037.

34. Dean BJ, Franklin SL, Murphy RJ, Javaid MK, Carr AJ. Glucocorticoids induce specific ion-channel-mediated toxicity in human rotator cuff tendon: a mechanism underpinning the ultimately deleterious effect of steroid injection in tendinopathy? Br J Sports Med. 2014 Dec;48(22):1620-6. doi:10.1136/ bjsports-2013-093178.

35. Osti L, Berardocco M, di Giacomo V, Di Bernardo G, Oliva F, Berardi AC. Hyaluronic acid increases tendon derived cell viability and collagen type I expression in vitro: Comparative study of four different Hyaluronic acid preparations by molecular weight. BMC Musculoskelet Disord 2015 Oct 6;16:284 . doi: 10.1186/s12891-015-0735-7.

36. Gallorini M, Berardi AC, Berardocco M, Gissi C, Maffulli N, Cataldi A, Oliva F. Hyaluronic acid increases tendon derived cell viability and proliferation in vitro: comparative study of two different hyaluronic acid preparations by molecular weight. Muscles Ligaments Tendons J 2017 Sep 18;7(2):208214. doi:10.11138/mltj/2017.7.2.208.

37. Oliva F, Piccirilli E, Bossa M, Via AG, Colombo A, Chillemi C, Gasparre G, Pellicciari L, Franceschetti E, Rugiero C, Scialdoni A, Vittadini F, Brancaccio P, Creta D, Buono AD, Garofalo R, Franceschi F, Frizziero A, Mahmoud A, Merolla G, Nicoletti S, Spoliti M, Osti L, Padulo J, Portinaro N, Tajana G, Castagna A, Foti C, Masiero S, Porcellini G, Tarantino U, Maffulli N. I.S.Mu.L.T - Rotator Cuff Tears Guidelines. Muscles Ligaments Tendons J 2016 Feb 13;5(4):227-63. doi: 10.11138/ $\mathrm{mltj} / 2015.5 .4 .227$.

38. Balint PV, Kane D, Hunter J, McInnes IB, Field M, Sturrock $\mathrm{RD}$. Ultrasound guided versus conventional joint and soft tissue fluid aspiration in rheumatology practice: a pilot study. $\mathrm{J}$ Rheumatol. 2002 Oct;29(10):2209-13.

39. Naredo E, Cabero F, Beneyto P, Cruz A, Mondéjar B, Uson J, Palop MJ, Crespo M. A randomized comparative study of short term response to blind injection versus sonographic-guided injection of local corticosteroids in patients with painful shoulder. J Rheumatol 2004 Feb;31(2):308-14. 
40. Lee HJ, Lim KB, Kim DY, Lee KT. Randomized controlled trial for efficacy of intra-articular injection for adhesive capsulitis: ultrasonography-guided versus blind technique. Arch Phys Med Rehabil. 2009 Dec;90(12):1997-2002. doi:10.1016/j. apmr.2009.07.025.
41. Cole BF, Peters KS, Hackett L, Murrell GA. Ultrasound-Guided Versus Blind Subacromial Corticosteroid Injections for Subacromial Impingement Syndrome: A Randomized, DoubleBlind Clinical Trial. Am J Sports Med. 2016 Mar;44(3):702-7. doi: $10.1177 / 0363546515618653$. 